\title{
Glial Cell Proliferation
}

National Cancer Institute

\section{Source}

National Cancer Institute. Glial Cell Proliferation. NCI Thesaurus. Code C26150.

Glial Cell Proliferation involves multiplication or reproduction through cell division of various types of glial cells, neural supportive cells in the central and peripheral nervous systems. 